\title{
Virulence associated factors and antibiotic sensitivity pattern of Escherichia coli isolated from cattle and soil
}

\author{
Singh Parul ${ }^{1}$, Basanti Bist ${ }^{1}$, Barkha Sharma ${ }^{2}$ and Udit Jain ${ }^{1}$ \\ 1. Department of Veterinary Public Health, College of Veterinary Sciences and Animal Husbandry, Uttar Pradesh Pandit Deen \\ Dayal Upadhyaya Pashu Chikitsa Vigyan Vishwavidyalaya Evam Go Anusandhan Sansthan (DUVASU), Mathura, India; \\ 2. Department of Veterinary Epidemiology, College of Veterinary Sciences and Animal Husbandry, DUVASU, Mathura, India. \\ Corresponding author: Parul Singh, email: parulkaler@rediffmail.com \\ Received: 23-03-2014, Revised: 18-04-2014, Accepted: 25-04-2014, Published online: 31-05-2014
}

doi: $10.14202 /$ vetworld.2014.369-372

How to cite this article: Parul S, Bist B, Sharma B and Jain U (2014) Virulence associated factors and antibiotic sensitivity pattern of Escherichia coli isolated from cattle and soil, Veterinary World 7(5): 369-372.

\begin{abstract}
Aim: The present study was conducted to isolate pathogenic Escherichia coli from the faeces of apparently healthy cattle and soil of the farms to determine their susceptibility to commonly used antibiotics.

Materials and Methods: A total of 90 samples ( 70 faecal and 20 soil samples) were collected aseptically and processed under required conditions for the isolation of $E$. coli. To confirm the isolates as $E$. coli, various biochemical tests like IMViC were performed. To assess the virulence of isolates, they were subjected to Congo red dye assay and hemolysis assay. Antibiotic sensitivity pattern of pathogenic isolates was studied by Disc diffusion method.

Results: The prevalence of $E$. coli was observed to be $85.71 \%$ and $20 \%$ from the faecal and soil samples, respectively. Based on the phenotypic characteristics on CT SMAC and MUG Sorbitol, none of the isolates were found to be E. coli O157. The percent positivity on Congo red dye assay was $44.28 \%$ for faeces and $5 \%$ for soil while only faecal $E$. coli $(4.28 \%)$ were found to be positive for hemolysis assay. The antibiogram of all 35 pathogenic isolates against 8 antibiotics showed that majority of pathogenic strains exhibited high level of sensitivity to Ceftriaxone (95\%), Ciprofloxacin (93\%), Amikacin (90\%), Gentamycin (89\%) and low level of sensitivity against Ampicillin (8\%) and Streptomycin (5\%). All isolates were 100\% resistant to Amoxicillin and Tetracycline.
\end{abstract}

Conclusion: Cattle act as main reservoirs of pathogenic $E$. coli that may enter the food chain by faecal contamination and pose potential public health hazards.

Keywords: alpha hemolysis, antibiogram, congo red dye assay, E. coli, virulence factor.

\section{Introduction}

Various studies have been conducted worldwide to isolate pathogenic bacteria that may be a cause of concern for human or animal health. Escherichia coli is such a commensal microbe which is the major part of normal aerobic microbial population of the intestine of humans and warm blooded animals. Its presence is considered as major indicator of faecal contamination in food and water [1]. Many of the strains of E. coli could emerge as pathogens due to the presence of certain pathogenic features and virulence genes which are located on transmissible genetic elements and this distinguishes them from ordinary commensal strains [2].

Pathogenic E. coli have become a significant health concern, especially $E$. coli $\mathrm{O} 157: \mathrm{H} 7$, which is associated with human diseases like hemorrhagic colitis (HC), haemolytic uraemic syndrome (HUS) and thrombocytic thrombocytopaenic purpura (TPP). Cattle is considered to be the major reservoir of many pathogenic E. coli especially serotype O157:H7. The contamination of raw milk, meat and their products by cattle faeces have been the cause of major foodborne

Copyright: The authors. This article is an open access article licensed under the terms of the Creative Commons Attribution License (http://creativecommons.org/licenses/by/2.0) which permits unrestricted use, distribution and reproduction in any medium, provided the work is properly cited. outbreaks all around the world. Antimicrobial drug resistance in bacterial isolates that have potential to enter our food supply is a growing public health concern. Antibiotics are being frequently incorporated as sub therapeutic and animal food supplements to cure and prevent disease in animals. This non judicious use of antibiotics generate a selective pressure that has led to the emergence of antibiotic resistance in the microbes including E. coli [3].

Considering the impact of pathogenic E. coli on humans, animals and its considerable public health significance, the present study was conducted to discern the virulence factors and antibiotic susceptibility profile of E. coli isolated from faeces of apparently healthy cattle as well as environment (soil) from dairy farms of Uttar Pradesh.

\section{Materials and Methods}

A total 90 samples comprising of 70 rectal swab samples of healthy adult crossbred dairy cows, and 20 soil samples were collected from two organised dairy farms located at Mathura and Bareilly districts of Uttar Pradesh in a period of one year from December 2012November 2013. For the soil sample collection, $1 \mathrm{~cm}$ deep in to the farm soil was dug and approximately 20 gm of soil collected where animals were housed. Isolation of $E$. coli was done as per the method described by 


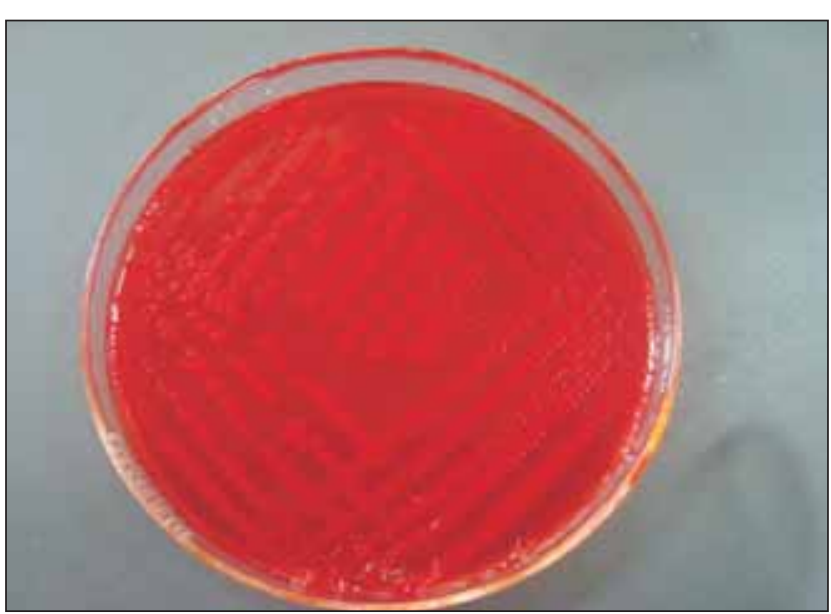

Figure-1: E. coli showing brick red colonies on Congo red medium

Merchant and Backer [4] with slight modification. One gm of faecal samples and $20 \mathrm{gm}$ of soil sample were collected aseptically and enriched with $10 \mathrm{ml}$ and $90 \mathrm{ml}$ trypticase soya broth (TSB) (containing $1 \mathrm{mg} / 100 \mathrm{ml}$ of acriflavin) respecti-vely for $18 \mathrm{hrs}$ at $37{ }^{\circ} \mathrm{C}$. Sub culturing was done using Mac Conkey's Agar (MLA) plates. Lactose fermenting, small, pink colonies were transferred to Eosin Methylene Blue (EMB) Agar plates for demonstration of characteristic "green metallic sheen" following incubation for $24 \mathrm{hrs}$ at $37^{\circ} \mathrm{C}$. Different biochemical tests like indole, methyl red, voges- proskauer, citrate, nitrate reduction, oxidase and sugar fermentation were performed by kit (KB010 Hi E. Coli identification kit, Himedia, India).

Phenotypic characterisation of isolates: Biochemically confirmed $E$. coli isolates were streaked over CT- SMAC (Cefixime tellurite sorbitol MacConkey Agar), and kept for incubation at $37^{\circ} \mathrm{C}$ for $24 \mathrm{hrs}$. E. coli $\mathrm{O} 157: \mathrm{H} 7$ produced sorbitol-non fermenting colorless colonies while non O157 fermented the sorbitol and appeared pink on this medium [5]. The isolates were also streaked on MUG sorbitol agar which differentiates E. coli O157 from non O157 [6]. E. coli $\mathrm{O} 157: \mathrm{H} 7$ which is glucuronidase negative did not show fluorescence while other $E$. coli fluoresced under UV light due to hydrolysis of 4-methylumbelliferyl- $\beta$-D glucuronidase (MUG) by the enzyme glucuronidase.

\section{In- vitro pathogenicity test of $E$. coli}

Congo red (CR) dye binding assay: Congo red (CR) dye binding assay is used as a phenotypic marker to distinguish between virulent and avirulent strains of $E$. coli. All isolates were streaked on Congo red agar medium comprising trypticase soya agar enriched with $0.05 \%$ Congo red dye and $0.15 \%$ bile salts and incubated at $37^{\circ} \mathrm{C}$ for $24 \mathrm{hrs}$. The plates were further incubated at room temperature for an additional $48 \mathrm{hrs}$. The CR positive $E$. coli isolates produced brick red colonies (Figure-1) which became wrinkled after 48 hrs at room temperature while CR negative $E$. coli did not bind the dye and produced white colonies [7].

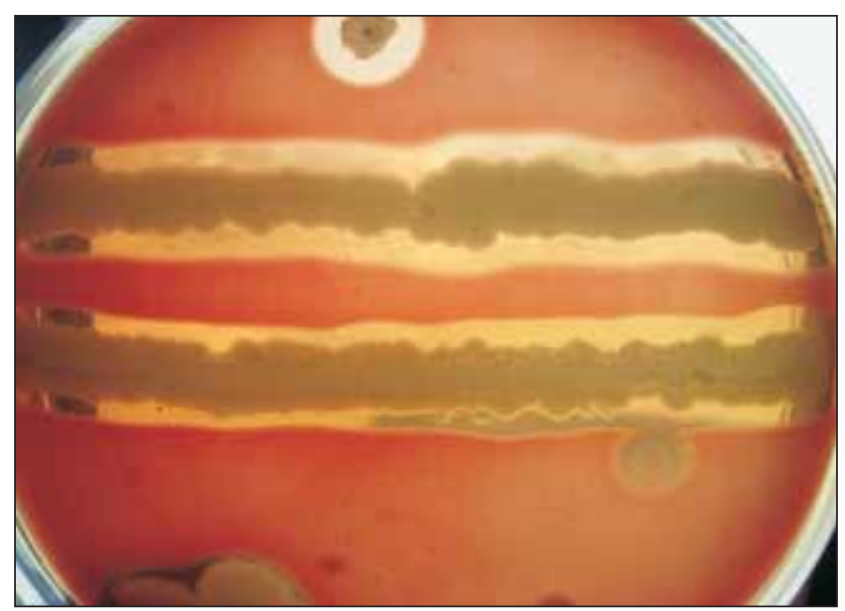

Figure-2: E. coli showing alpha hemolysis on washed sheep blood agar

Verotoxic E. coli serotype O26 and strain ATCC 25992 were used as positive and negative controls respectively, for this assay.

Hemolysis assay: The ability of certain $E$. coli strains to lyse erythrocytes of mammalian species is termed as hemolysis [8]. Four different types of hemolysins viz alpha, beta, gamma and enterohemolysin (E-hly) are produced by different pathogroups of E. coli. Alpha hemolysin (Hly), considered as a prototype of a large family of pore-forming toxins, named repeat in toxin (RTX), is a cell free factor which causes clear zone around colonies on blood agar plates within 4-8 hrs of incubation [9]. To assess the haemolytic properties of E. coli isolates, all were streaked on 5\% washed sheep blood agar supplemented with $10 \mathrm{mM} \mathrm{CaCl}_{2}$. E. coli serotype O34 and strain ATCC 25992 were used as positive and negative controls respectively, for this assay. Positive isolates produced clear zone of hemolysis (Figure-2).

Antimicrobial sensitivity of $E$. coli: In-vitro antibiogram of all the pathogenic isolates was performed by Disc diffusion method [10] on Muller Hinton agar. Isolates were tested against 8 commonly used antibiotics

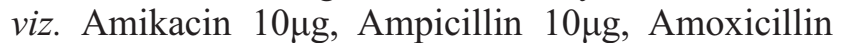
$10 \mu \mathrm{g}$, Cefotaxime $5 \mu \mathrm{g}$, Ciprofloxacin 10 $\mu \mathrm{g}$, Gentamycin $10 \mu \mathrm{g}$ Streptomycin $10 \mu \mathrm{g}$ and Tetracycline $10 \mu \mathrm{g}$. Zones of complete inhibition were measured according to standards of Clinical Laboratory Standard Institute (CLSI). E. coli Strain ATCC 25992 was used as a negative control.

\section{Results}

Out of 70 faecal and 20 soil samples which were screened for isolation of $E$. coli, a total of 64 isolates (60 from faeces and 4 from soil) were obtained which were biochemically confirmed. The prevalence of $E$. coli was found to be $85.71 \%$ and $20 \%$ from the faeces and soil, respectively. For the isolation of pathogenic $E$. coli serotype O157, all 64 isolates were streaked over CT SMAC and resulting colorless colonies were further transferred to MUG sorbitol. None of the isolates 
Table-1. Antimicrobial susceptibility pattern of $E$. coli isolate from cattle faeces and soil

\begin{tabular}{|c|c|c|c|}
\hline Antibiotic & No. of isolates tested & Sensitivity \% & Resistance \% \\
\hline Amikacin (AK) & 35 & 90 & 10 \\
\hline Ampicillin(AMP) & 35 & 8 & 92 \\
\hline Amoxycillin(AMX) & 35 & 0.0 & 100 \\
\hline Ceftriaxone(CTR) & 35 & 95 & 5 \\
\hline Ciprofloxacin(CIP) & 35 & 93 & 7 \\
\hline Gentamycin(GEN) & 35 & 89 & 11 \\
\hline Streptomycin(S) & 35 & 5 & 95 \\
\hline Tetracycline(TE) & 35 & 0.0 & 100 \\
\hline
\end{tabular}

were found to be non-fluorescent on MUG sorbitol showing a zero prevalence of O157. To assess the invitro pathogenicity, all 64 isolates were subjected to Congo red dye binding (CR) and hemolysis assay. A total of 35 isolates ( 31 faecal and 4 soil isolates) were positive on CR assay while on sheep blood agar only 3 faecal isolates and none from soil produced the desired clear zone of alpha hemolysis. The percent positivity of CR assay was $44.28 \%$ for faeces and $5 \%$ for soil while only faecal E. coli (4.28\%) were found to be positive for hemolysis assay. The result of antimicrobial sensitivity pattern of all 35 pathogenic isolates against 8 commonly used antibiotics are presented in Table- 1 . The majority of pathogenic strains exhibited a high level of sensitivity to Ceftriaxone, Ciprofloxacin, Amikacin and Gentamycin and low level of sensitivity against Ampicillin and Streptomycin. All the isolates showed $100 \%$ resistance to Amoxicillin and Tetracycline.

\section{Discussion}

In the present study prevalence of $E$. coli in cattle faeces was reported to be $85.71 \%$ while it was found to be $20 \%$ in soil. Similar results were obtained by Fluckey et al. [11], while lower prevalence of E. coli was found by Elseisy et al. [12] and Ahmed et al. [13]. The variation in the prevalence of $E$. coli in various studies might be due to the influence of different factors like age, sex, breed, place and probably seasons. A wide range of prevalence ( 0.2 to $48.9 \%$ ) of O157 from cattle faeces has been reported worldwide [14]. In the present study, prevalence of $\mathrm{O} 157$ was found to be zero which is almost similar to the lower limit of wide range of prevalence $(0.2$ to $48.9 \%)$ of $\mathrm{O} 157$ reported from cattle faeces worldwide. Thran et al. [15] and Scott et al. [16] also reported the zero prevalence of $\mathrm{O} 157$ in cattle faeces.

Congo red dye binding (CR) assay could be used as phenotypic marker to distinguish invasive and non invasive strains of $E$. coli. CR assay had been studied by various workers $[7,17,18]$ and all of them found $50 \%$ isolates from poultry and environmental sources to be positive for this assay. In the present study, $44.28 \%$ and $5 \%$ isolates from cattle faeces and soil, respectively, were found to be CR positive. There are only few studies on CR assay of E. coli of bovine origin. Sharma et al. [19] found $47.42 \%$ positive value which was in accordance to our study while a much higher value ( $89 \%$ ) was obtained by Elseisy et al. [12] and a much lower positivity (20.4\%) was obtained by
Kalorey et al. [20].

Alpha-hemolysin (Hly) is a common exotoxin produced by $E$. coli that enhances virulence in a number of clinical infections of animals [21]. It is a cell free haemolytic factor which produces large clear zones of haemolysis often apparent after $4 \mathrm{hrs}$ of incubation on washed or unwashed sheep blood agar [22]. The alpha-haemolysin has activity against human lymphocytes [23]. Enterohemolysin (E-hly) generally produced by VTEC group of E. coli are pathogenic to humans. There is approximately $60 \%$ relatedness between E-hly and (Hly) and both haemolysins belong to the RTX family of toxins [23]. In this study, alpha hemolysis was produced by $4 \%$ isolates of faecal origin and none of the soil isolates showed this characteristic. The findings are in agreement with various worker Lorenz et al. [24] and Shekh et al. [25] showed 2.8\% haemolytic activity while high haemolytic activity observed in study of Elseisy et al. [12] as 34\%.

All 35 pathogenic $E$. coli isolates from faeces and soil samples subjected to antimicrobial sensitivity profile, showed high resistance to Ampicillin, Amoxicillin, Streptomycin and Tetracycline. The findings of present study are in agreement with earlier reports [3, 26, 27]. High level of sensitivity was reported to Amikacin, Ciprofloxacin, Ceftriaxone and Gentamycin this was in accordance to the finding of Romanus et al. [28] and Zinnah et al. [29], while many workers have found contrasting results as in the studies of Fluckey et al [11] and Joshi et al. [30]. This increasing resistance pattern of $E$. coli may be attributed to the over use and non judicious use of various antimicrobials. Commensal $E$. coli face various selective pressures in the environments of intestine which further favours the development, persistence and dissemination of robust strains that may be resistant to antimicrobial agents.

\section{Conclusion}

Pathogenic E. coli isolated from cattle faeces and soil may contaminate the food chain and may be a source of major public health hazards. Antibiotic resistant organisms that are constantly shed into the environment through the faeces of apparently healthy cattle may cause serious antibiotic resistant infections to human beings. So decisive efforts must be made to maintain hygienic conditions at dairy farms and at food processing plants. The high prevalence of antimicrobial resistance among strains of $E$. coli depicts the immense need for strict measures to regulate the use of antimicrobials within the food chain. 


\section{Author's contributions}

SP, BB, BS and UJ executed the study design and analysed the data. SP performed the entire study under the guidance of BB. SP drafted and revised the manuscript with the help of BS and UJ. All authors read and approved the final manuscript.

\section{Acknowledgements}

The authors wish to express their heartfelt thanks to the Indian Council of Agricultural Research, New Delhi, India for providing funds and necessary facilities through the project entitled "Outreach research programme on zoonotic diseases on Vero cytotoxic $E$. coli" to carry out part of the research work.

\section{Competing interests}

The authors declare that they have no competing interests.

\section{References}

1. Karmali, M.A., Gannon, V. and Sargeant, J.M. (2010) Verocytotoxin-producing Escherichia coli (VTEC). Vet. Microbiol. 140:360-370.

2. Ronsengren, L.B., Waldner, C.L. and Reid-Smith, R.J. (2009) Association between antimicrobial resistance phenotypes, antimicrobial resistance genes and virulence genes of faecal E. coli isolates of healthy grown finish pigs. Applied Environ. Microb. 75: 1373-1380.

3. Ajayi, A.O., Oluyege, A.O., Olowe, O.A and Famurewa, O. (2011) Antibiotic resistance among commensals Escherichia coli isolated from faeces of cattle in Ado- Ekiti, Nigeria. $J$. Ani. Vet. Adv. 10(2): 174-179.

4. Merchant, I.A. and Packer, R.A. (1967) Veterinary Bacteriology and Virology. $6^{\text {th }}$ Ed. Iowa State University Press, USA. p752.

5. Park, S.H, Ryu, S. and Kang, D.H. (2011) Improved selective and differential medium for isolation of Escherichia coli O157:H7. J. Clin. Microbiol 49(1): 405-408.

6. Thomas, K.M., McCann, M.S., Collery, M.M., Logan, A., Whyte, P., McDowell, D.A. and Duffy, G. (2012) Tracking verocytotoxigenic Escherichia coli O157, O26, O111, O103 and O145 in Irish cattle. Int. J. Food Microbiol. 153:288-296.

7. Savita., Kusumakar, A.L. and Malik, Y.P.S. (2007) Prevalence of diarrheagenic Escherichia coli and Salmonella among poultry in Madhya Pradesh. Indian J. Anim. Sci. 77 (10): 933-936.

8. Beutin, L. (1991) The different hemolysins of Escherichia coli.Med. Microbiol.Immunol. 180:167-182.

9. Sanchez, S., Bakás, L., Gratton, E. and Herlax, V. (2011) Alpha hemolysin induces an increase of erythrocytes calcium: A FLIM 2-Photon phasor analysis approach. PLoS ONE 6(6): e21127. doi:10.1371/journal.pone.0021127.

10. Bauer, M.E. and Welch, R.A. (1996) Characterization of an RTX toxin from enterohemorrhagic Escherichia coli O157:H7. Infect Immun. 64: 167-175.

11. Fluckey, W.M., Loneragan, G.H., Warner,R and Brashears, M. M. (2007) Antimicrobial drug resisitance of Salmonella And Escherichia coli isolated from cattle feces, hide and carcasses. J. Food. Prot. 70(3): 551-556.

12. Elseisy, A.G., Khaliel, S.A., Khadr, A.M. and Abdellrazeq, G.S. (2010) Serotypes and virulence genes of Shiga toxin producing Escherichia coli isolated from cattle. Alex. J. Vet. Sci. 32: 163-173.

13. Ahmed, R., Ali, A., Demczuk, W., Woodward, D., Clark, C., Khakhria, R. and Rofgers, F. (2000) Emergence of new molecular and phage typing variants of E. coli $\mathrm{O} 157: \mathrm{H7}$ in Canada. In Abstracts $4^{\text {th }}$ International Symposium and Workshop on Shiga toxin (Verocytotoxin) Producing
Escherichia coli Infections. Kyoto, Japan.

14. Hussein, H. S. and Sakuma, T. (2005) Prevalence of Shiga toxinproducing Escherichia coli in dairy cattle and their products. J. Dairy Sci. 88:450-465.

15. Thran, B.H, Hussein, H.S., Hall, M.R and Khaiboullina, S.F. (2001) Occurrence ofVerotoxin-producing Escherichia coli in dairy heifers an irrigated pasture. Toxicology.159-169.

16. Scott, L., Mcgee, P., Walsh, C.,Fanning, S., Sweeney, T., Blanco, J., Karczmarczyk, M., Earley, B., Leonard, N and Sheridan, J.J. (2009) Detection of numerous verotoxigenic E. coli serotypes, with multiple antibiotic resistance from cattle faeces and soil. Vet. Microbiol. 134:288-293.

17. Berkhoff, H. A. and Vinal, A. C. (1986) Congo red medium to distinguish between invasive and non invasive Escherichia coli pathogenic for poultry. Avian Dis. 30: 117-121.

18. Panigarhy, B. and Yushen, L. (1990) Differentiation of pathogenic and non pathogenic Escherichia coli isolated from poultry. Avian Dis. 34: 941-943.

19. Sharma, K.K., Soni, S.S. and Meharchandani, S. (2006) Congo red dye agar test as an indicator test for detection of invasive bovine Escherichia coli. Vet. Arhiv 76:363-366.

20. Kalorey, D.R., Kurkene, N.V., Hame, S. D., Ingle, V. C., Patil, A.A., Sakhare, P.S, and Warke, S.R. (2002) Congo red binding ability of Escherichia coli. Indian J. Comp. Microbiol. Immunol. Infect. Dis. 23: 79-80.

21. Addison, K.M., Thomas, G.G., Robert, G.S. and Timothy, L.P. (2000) Contribution of Escherichia coli AlphaHemolysin to bacterial virulence and to intraperitoneal alterations in peritonitis. Infect Immun. 68(1): 176-183.

22. Karch, H., Schmidt, H. and Brunder,W. (1998) Plasmidencoded determinants of Escherichia coli O157:H7. In Escherichia coli O157:H7 and Other Shiga-ToxinProducing E. coli Strains ed.Kaper, J.B. and O'Brien, A.D. p183-194. Washington, DC:American Society for Microbiology.

23. Bauer, A.W., Kirby, W.M.M., Sherris, J.C. and Turck, M. (1966) Antibiotic susceptibility testing by a standardized single disc method. Am. J. Clin. Pathol. 45(4): 493-496.

24. Lorenz, S.C., Son, I., Maounounen, L.A., Lin, A., Fischer, M. and Kase, J.A. (2013) "Prevalence of Hemolysin Genes and Comparison of ehxA Subtype Patterns in Shiga ToxinProducing Escherichia coli (STEC) and Non- STEC Strains from Clinical, Food, and Animal Sources". Public Health Resources. Paper 289.

25. Shekh, C.S., Deshmukh, V.V., Waghamare, R.N., Markandeya, N.M. and Vaidya, M.S. (2013) Isolation of pathogenic E. coli from buffalo meat sold in Parbhani city, Maharashtra, India, Vet. World 6(5):277-279.

26. Abdullah, M., Akter, M.R., Kabir1, S.M.L., Khan, M.A.S. and Aziz, M.S.I.A. (2013) Characterization of bacterial pathogens isolated from calf diarrhoea in Panchagarh District of Bangladesh. J. Agric. Food. Tech. 3(6): 8-13.

27. Lim, S.K., Lee H.S., Nam, H.M., Cho, Y.S., Kim, J.M., Song, S.W., Park, Y.H. and Jung, S.C. (2007) Antimicrobial resistance observed in Escherichia coli strains isolated from fecal samples of cattle and pigs in Korea during 2003-2004. Int. J. Food Microbiol. 116:283-286.

28. Romanus, I. I., Chinyere, O.E., Amobi, N.E., Anthonia, O.E., Ngozi, A.F., Chidiebube, N.A. and Eze, A.T. ( 2012) Antimicrobial resistance of Escherichia coli isolated from animal and human clinical sample. Glo. Res. J. Microbiol. 2 (1):85-89.

29. Zinnah, M.A., Haque, M.H., Islam, M.T., Hossain, M.T., Bari, M.R., Babu, S.A.M., Rahman, M. T. and Islam, M.A. (2008) Drug sensitivity pattern of Escherichia coli isolated from samples of different biological and environmental sources. Bangl.J. Vet. Med.. 6(1): 13-18.

30. Joshi, B.P., Pociecha, J.Z. and Yousif, Y.A. (1986) Drug sensitivity pattern of organisms isolated from calf colibacillosis in Mosul (Iraq). Indian Vet. J. 63: 783-784. 